\title{
Enhanced Production of Neutrophil-activating Peptide-1/Interleukin-8 in Rheumatoid Arthritis
}

\author{
Michael Seitz, ${ }^{\star}$ Beatrice Dewald, ${ }^{*}$ Niklaus Gerber, ${ }^{\star}$ and Marco Baggiolini ${ }^{\ddagger}$ \\ *Division of Rheumatology, University Clinic, Inselspital, Bern, Switzerland; \\ and ${ }^{\ddagger}$ Theodor-Kocher Institute, University of Bern, Bern, Switzerland
}

\begin{abstract}
Production of the neutrophil-activating peptide (NAP)-1/IL-8 by mononuclear phagocytes from patients with RA and from control subjects was studied under various conditions. Mononuclear cells from bone marrow (BMMC), PBMC, and synovial fluid (SFMC) were cultured for up to $48 \mathrm{~h}$ in the absence or presence of Escherichia coli LPS, different interleukins, interferon-gamma, zymosan, or immune complexes, and the neutrophil-stimulating activity released into the culture medium was determined. As shown by neutralization with an antiserum raised against human recombinant NAP-1/IL-8, over $90 \%$ of this activity could be attributed to NAP-1/IL-8.

In unstimulated mononuclear cells from control individuals and BMMC from RA patients, the production of NAP-1/IL-8 was very low and was enhanced moderately by stimulation with LPS. By contrast, the spontaneous production of NAP-1/IL-8 was 3- to 10-fold higher in PBMC and even much higher in SFMC from RA patients. In all instances, the yield of NAP-1/ IL-8 could be enhanced by stimulation in culture. In addition to LPS, rheumatoid factor-containing immune complexes, zymosan, and IL-1 were highly effective in inducing NAP-1/IL-8 production, while IL-3, GM-CSF, tumor necrosis factor (TNF), and IL-2 were somewhat less potent. An inhibitory effect was obtained with IFN-gamma, which significantly decreased the spontaneous NAP-1/IL-8 release from SFMC and the IL-1- and LPS-induced NAP-1/IL-8 from RA and control PBMC. Inhibition was also observed with glucocorticoids. The production of NAP-1/IL-8 was markedly reduced by dexamethasone in phagocytosis-stimulated PBMC, and almost totally inhibited in SFMC obtained from joints after intraarticular administration of betamethasone. By contrast, the cyclooxygenase inhibitor, indomethacin, tended to increase the NAP-1/IL8 yield from PBMC in culture. (J. Clin. Invest. 1991. 87:463469.) Key words: mononuclear phagocytes $\bullet$ peripheral blood • synovial fluid $\bullet$ immune complexes $\bullet$ cytokines
\end{abstract}

\section{Introduction}

Neutrophil migration and activation at inflammatory sites depend on a complex series of interrelated humoral and cellular control mechanisms that regulate the generation and expres-

Address correspondence and reprint requests to Dr. Michael Seitz, Division of Rheumatology, Inselspital, CH-3010 Bern, Switzerland.

Received for publication 21 March 1990 and in revised form 13 August 1990.

J. Clin. Invest.

(c) The American Society for Clinical Investigation, Inc.

$0021-9738 / 91 / 02 / 0463 / 07 \$ 2.00$

Volume 87, February 1991, 463-469 sion of neutrophil directed stimuli and modulate the activity of the responding cells. In RA, neutrophils migrating into the synovial membrane and the synovial fluid may be exposed to a number of mediators such as C5a formed upon complement activation (1) and several products secreted by endothelial and/ or mononuclear cells like platelet-activating factor, leukotriene $\mathrm{B}_{4}(2,3), \mathrm{IL}-1$, and tumor necrosis factor-alpha $(\mathrm{TNF})^{1}(4,5)$. Neutrophils contain a wide spectrum of cartilage-degrading enzymes (6) which, upon stimulation, can be released along with cytotoxic oxygen metabolites. Activated neutrophils, therefore, may contribute, besides mononuclear phagocytes, chondrocytes, and other cells, to tissue damage at sites of inflammation.

A novel monocyte-derived cytokine that specifically interacts with neutrophils has been described recently. Purification and sequence analysis studies performed in several laboratories led to the identification of a 72-amino acid peptide, that initially became known as MDNCF for monocyte-derived neutrophil chemotactic factor (7), MONAP for monocyte-derived neutrophil-activating peptide (8) and NAF for neutrophil-activating factor (9). Presently the term neutrophil-activating peptide (NAP)-1/IL-8 is most widely accepted (10). NAP- $1 / \mathrm{IL}-8$ presumably plays a major role in neutrophil diapedesis through vascular endothelium and focal recruitment at inflamed sites. This notion is supported by the observation that upon exposure to IL-1 or TNF, endothelial cells not only express adhesion proteins $(11,12)$ that promote their interaction with circulating neutrophils, but also produce NAP-1/IL-8 $(13,14)$. In addition, human fibroblasts express NAP-1/IL-8 mRNA in response to IL-1 or TNF (15), and human synovial cells release neutrophil-stimulating activity when challenged with IL-1 (16). NAP-1/IL-8 is also effective in vivo. Intradermal injection in rabbits results in plasma exudation and massive neutrophil infiltration (17). Similar observations were made in rats, mice, guinea pigs, and dogs (Zwahlen, R., et al., manuscript in preparation)

We have studied the production of NAP-1/IL- 8 by mononuclear phagocytes obtained from RA patients and healthy individuals. These results show that blood and synovial mononuclear phagocytes from RA patients, in contrast to blood monocytes from control individuals, release NAP-1/IL-8 spontaneously, and that NAP-1/IL- 8 production by these cells is further enhanced by stimulation in culture.

\section{Methods}

Subjects. 43 patients satisfying the American Rheumatism Association criteria for RA (18) were included in this study. 34 were seropositive

1. Abbreviations used in this paper: BMMC and SFMC, bone marrow and synovial fluid mononuclear cells; hrNAP, human recombinant neutrophil-activating peptide; GM-CSF, granulocyte/macrophage colony-stimulating factor; RF-IC, rheumatoid factor-containing immune complexes; TNF, tumor necrosis factor. 
and 9 seronegative according to latex fixation and Waaler-Rose tests for rheumatoid factor. All patients received nonsteroidal antiinflammatory drugs. Additional medication was low dose steroids (prednisone $7.5 \mathrm{mg} / \mathrm{d}$ or less; 16 patients), gold salts (14 patients), D-penicillamine (6 patients), chloroquine diphosphate (6 patients), or salazopyrine ( 2 patients). None of the patients received immunosuppressants. The control population consisted of 24 healthy hospital workers and 19 patients with degenerative spine disease of which only 8 received analgesics. Disease duration in RA patients was 0.5-12 yr. Patients with other diseases, in particular intercurrent infections, were excluded.

Cell preparations. Mononuclear cells were isolated from heparinized bone marrow blood ( 4 control subjects and 4 RA patients), heparinized venous blood (43 control subjects and 43 RA patients), and knee synovial fluid (12 RA patients) by standard Ficoll-Hypaque fractionation (19). The cells were washed three times in PBS and resuspended in culture medium $\left(10^{6}\right.$ cells $\left./ \mathrm{ml}\right)$. Cell viability was tested by trypan blue exclusion (90-96\% viable cells) and the number of monocytes (varying between 16-54\%) was determined after staining for nonspecific esterase (20) and by the monoclonal antibody Leu M3 (Becton Dickinson, Heidelberg, FRG). Monocyte content was $16-28 \%$ in PBMC from healthy controls, 26-54\% in PBMC, and $24-36 \%$ in SFMC from RA patients. Routinely, total mononuclear cell fractions were cultured. In a few selected experiments isolated monocytes prepared by adherence (25) were also used.

Culture conditions. The culture medium consisted of DMEM supplemented with $100 \mathrm{IU} / \mathrm{ml}$ penicillin/streptomycin (Gibco AG, Basel, Switzerland), $25 \mathrm{mM} \mathrm{NaHCO}_{3}, 20 \mathrm{mM}$ Hepes, $200 \mathrm{mM}$ L-glutamine, and $1 \%$ pasteurized plasma protein solution (5\% PPL SRK; Swiss Red Cross Laboratory, Bern, Switzerland). $2 \times 10^{5}$ cells in $0.2 \mathrm{ml}$ medium were incubated in flat bottom microtiter plates (Nunc, Roskilde, Denmark) in a humidified atmosphere of $5 \% \mathrm{CO}_{2}$ at $37^{\circ} \mathrm{C}$ for 8,24 , or $48 \mathrm{~h}$. From each well, duplicate portions of $50 \mu \mathrm{l}$ of the cell-free medium were then transferred to a second plate for determination of neutrophilstimulating activity, and stored at $-70^{\circ} \mathrm{C}$ until use. Where indicated, culturing was performed in the presence of various human recombinant cytokines. The following concentrations, which had previously been shown to induce optimum production of NAP-1/IL-8 in PBMC and SFMC, were used: IL-1-beta $(10 \mathrm{ng} / \mathrm{ml}$; Glaxo, Geneva, Switzerland), IL-2 (200 U/ml; Glaxo), granulocyte/macrophage colony-stimulating factor (GM-CSF) (100 U/ml; Sandoz Ltd., Basel, Switzerland), IL-3 (100 U/ml; Sandoz Ltd.), TNF-alpha (10 ng/ml; Hoffmann-La Roche Ltd., Basel, Switzerland), and IFN-gamma (100 U/ml; Biogen, Laupheim, FRG). In addition, $E$. coli LPS (100 ng/ml; Gibco AG), zymosan and/or C3b-opsonized zymosan $(1 \mathrm{mg} / \mathrm{ml}$; Sigma Chemical Co., Munich, FRG), and immune complexes (see below) were used as stimuli. In some experiments, polymyxin B (100 U/ml; Sigma Chemical Co.) was used to prevent possible LPS effects. Solutions were made in pyrogen-free PBS or saline.

Preparation of immune complexes. Immune complexes were freshly prepared for each experiment. Heat-aggregated IgG (IgG-IC) was obtained by heating $10 \mathrm{mg} / \mathrm{ml}$ human IgG (Sigma Chemical Co.) for $60 \mathrm{~min}$ at $63^{\circ} \mathrm{C}$. After centrifugation at $15,000 \mathrm{rpm}$ for $15 \mathrm{~min}$ and washing three times in PBS, the IgG aggregates were suspended in saline. To obtain rheumatoid factor-containing immune complexes (RFIC) $10 \mathrm{mg}$ human IgG was heat aggregated and then incubated overnight at $4^{\circ} \mathrm{C}$ with $10 \mathrm{ml}$ serum from an individual RA patient with a Waaler-Rose titer of at least 1:256. In parallel, $10 \mathrm{mg}$ heat-aggregated human IgG was incubated with $10 \mathrm{ml}$ normal serum from a young healthy donor containing neither IgM nor IgG rheumatoid factors (IC). RA and normal sera were not decomplemented. The cryoprecipitates were centrifuged at 15,000 rpm for $15 \mathrm{~min}$, washed three times in PBS, and finally suspended in saline. IgG-IC, RF-IC, and IC were used at 10 $\mu \mathrm{g} / \mathrm{ml}$ after preliminary experiments performed with 1,10 , and 100 $\mu \mathrm{g} / \mathrm{ml}$ had shown maximum stimulation of NAP-1/IL-8 release from PBMC of controls and RA patients and from SFMC at $10 \mu \mathrm{g} / \mathrm{ml}$.

$N A P-1 / I L-8$ bioassay. A microtiter plate assay for elastase release from human neutrophils treated with cytochalasin B was used to determine neutrophil-stimulating activity (21). Each assay was calibrated with standard concentrations (0.1-30 $\mathrm{nM})$ of human recombinant NAP-1/IL-8 (hrNAP-1/IL-8) (22). The neutrophil-stimulating activity in the culture supernatants was expressed in NAP-1/IL-8 equivalents, as calculated from the amount of hrNAP-1/IL-8 inducing the same level of elastase release. This value was adjusted for $2 \times 10^{5}$ monocytes on the basis of the number of monocytes determined in the mononuclear cell preparation used.

Anti-NAP-1/IL-8 antiserum was kindly provided by S. L. Kunkel, University of Michigan Medical School, Ann Arbor, MI. Neutralization of the biological activity of NAP-1/IL-8 was shown in bioassays performed in the presence and absence of NAP-1/IL-8 antiserum (diluted 1:500).

Statistics. The statistical evaluation of the data was performed by the Mann-Whitney ranked-sum test.

\section{Results}

Spontaneous release of neutrophil-stimulating activity. PBMC and SFMC were cultured for up to $48 \mathrm{~h}$, and neutrophil-stimulating activity was determined in the medium. As shown in Fig. $1 A$, the activity increased linearly in a time-dependent manner with PBMC from both healthy individuals and RA patients. The yield obtained with cells from RA patients was 3- to 10fold higher than that of the controls and showed marked interindividual variations. Similar results were obtained with cultures of isolated monocytes instead of mononuclear cell fractions. By far the highest yields, however, were observed with the mononuclear cells from the synovial fluid. As shown by direct comparison, SFMC produced 6-10 times more neutrophil-stimulating activity than PBMC from the same RA patients (Fig. $1 \mathrm{~B}$ ). In accordance with this finding, NAP-1/IL-8 was detected in the synovial fluid of six RA patients $(0.2-5.0$ $\mathrm{pmol} / \mathrm{ml})$.

Effect of LPS. It has been repeatedly shown that LPS is one of the most potent inducers of NAP-1/IL-8 in human monocytes (10). In this study we found that LPS also enhanced the production of neutrophil-stimulating activity by mononuclear cells from RA patients. LPS had maximum effects at concentrations of $1 \mathrm{ng} / \mathrm{ml}$ with cells from RA patients and $5-10 \mathrm{ng} / \mathrm{ml}$ with cells from control individuals, and was used routinely at $100 \mathrm{ng} / \mathrm{ml}$. The LPS-dependent induction of neutrophil-stimulating activity in mononuclear cells from different sources is shown in Fig. 2. The response of bone marrow-derived cells was moderate and of similar extent for controls and RA patients. With PBMC the effect was more pronounced, and higher yields of neutrophil-stimulating activity were consistently obtained with PBMC from RA patients. The strongest responses were observed with SFMC. In each single experiment LPS significantly enhanced the production of neutrophilstimulating activity, and the degree of enhancement was independent of the level of spontaneous production.

Effects of different cytokines, immune complexes and phagocytosis. In order to identify mediators that might induce the production of neutrophil-stimulating activity within rheumatoid joints, PBMC and SFMC were cultured in the presence of a variety of cytokines that are known to be formed in the inflamed synovium. In addition, RF-IC, LPS, and zymosan particles were used as stimuli. As shown by the yield after $24 \mathrm{~h}$ and in particular after $48 \mathrm{~h}, \mathrm{RF}-\mathrm{IC}$, LPS, zymosan, IL-1, IL-3, and GM-CSF are powerful inducers of neutrophil-stimulating activity in PBMC both from control individuals and RA patients. Since similar effects were observed with either non-opsonized or C3b-opsonized zymosan, only data obtained with non-op- 

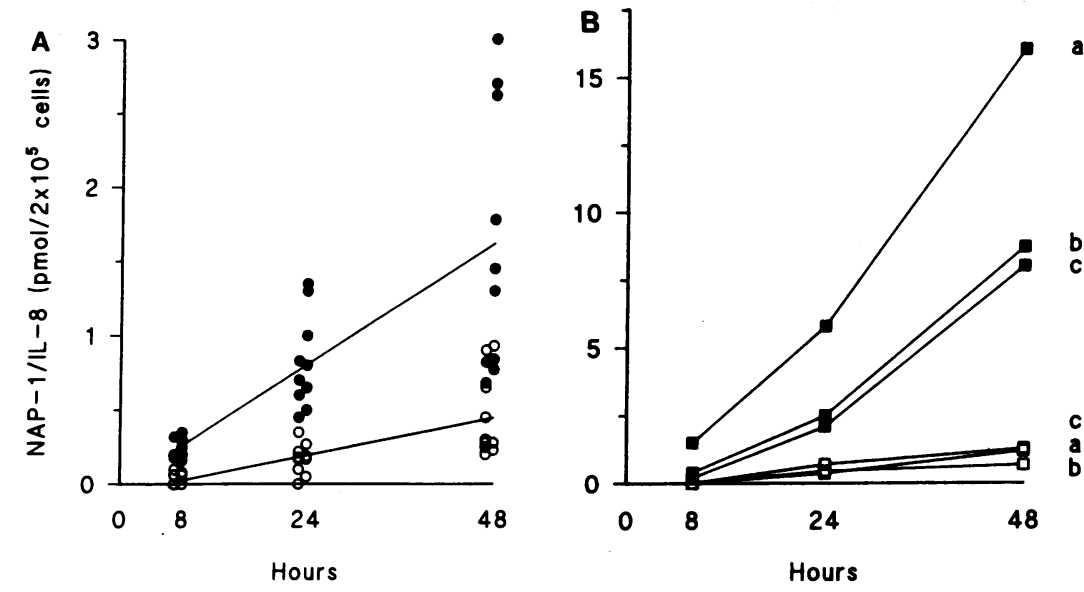

Figure 1. Time course of spontaneous release of neutrophil-stimulating activity from mononuclear cells. (Left) PBMC from ten normal subjects (O) and ten RA patients ( $\bullet$ ) were cultured for 8,24 , and $48 \mathrm{~h}$ and the culture supernatants were tested for NAP-1/IL-8-like activity. The difference between controls and RA patients was statistically significant $(P<0.001)$. (Right) Spontaneous release of neutrophil-stimulating activity by PBMC ( $\square$ ) and SFMC ( $(\mathbf{a})$ from three RA patients $(a, b, c)$. Neutrophil-stimulating activity is expressed as described in Methods. sonized particles are presented. IFN-gamma, TNF, and IL-2 were less potent (Fig. $3 \mathrm{~A}$ ). In agreement with the results obtained with LPS, all stimuli were more effective on PBMC from RA patients than from healthy individuals. The difference was statistically significant in all cases. A similar pattern of responses was observed with SFMC with the notable exception of IFN-gamma which was inhibitory (Fig. 3 B). In SFMC, RF-IC, IL-1, and LPS were the most effective stimuli.

In view of the high stimulatory effect of RF-IC, three different immune complex preparations (RF-IC, IC, IgG-IC) were compared in a further series of experiments. As shown in Table I, all preparations were active, and similar effects were obtained with IC and IgG-IC as with RF-IC on PBMC from RA patients and normal controls.

To exclude the possibility of LPS contamination as a cause of stimulation, the effects of polymyxin $B$, added at $100 \mathrm{U} / \mathrm{ml}$ to immune complex, cytokine, and zymosan preparations,

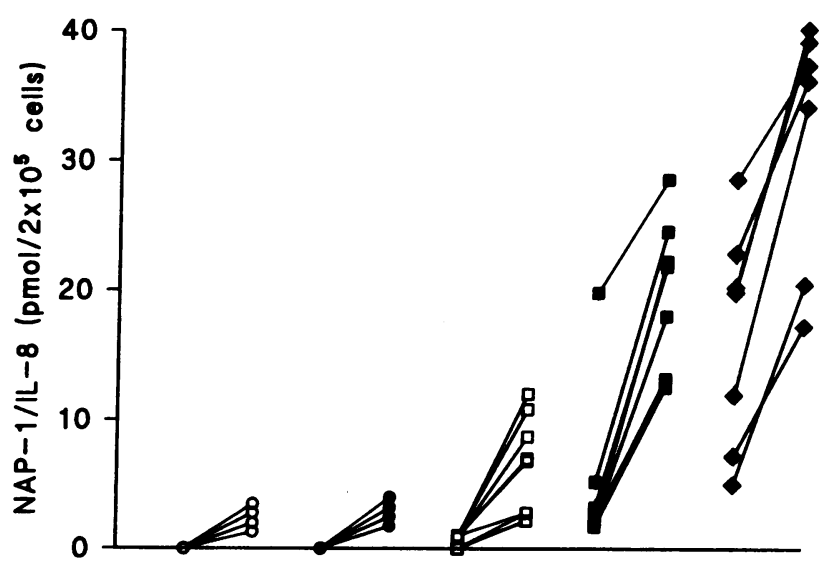

Figure 2. Spontaneous and LPS-induced release of neutrophilstimulating activity from BMMC, PBMC, and SFMC. BMMC from four control subjects (O) and RA patients (๑), PBMC from eight control subjects ( $\square$ ) and RA patients ( $\bullet$ ), and SFMC from seven RA patients $(\diamond)$ were cultured for $48 \mathrm{~h}$ with or without $100 \mathrm{ng} / \mathrm{ml}$ LPS (left and right in each group, respectively). Significant differences were observed between spontaneous release by PBMC and SFMC ( $P$ $<0.05)$ and BMMC and PBMC $(P<0.001)$ from RA patients as well as between LPS-induced release by BMMC and PBMC from control subjects and RA patients $(P<0.005)$. were studied. Polymyxin B decreased the effect of $100 \mathrm{ng} / \mathrm{ml}$ LPS by at least $80 \%$, but did not influence the response to the other stimuli. Polymyxin B also did not affect the release of neutrophil-stimulating activity by control and RA PBMC in the absence of added stimuli (data not shown).

$N A P-1 / I L-8$ identification. To show unequivocally that the neutrophil-stimulating activity in the culture supernatants corresponded to NAP-1/IL-8, neutralization experiments with an antiserum raised against hrNAP-1/IL-8 (anti-NAP-1/IL-8) were performed. As shown in Table II $A$, anti-NAP-1/IL-8 prevented elastase release by human neutrophils induced by hrNAP-1/IL-8, but not by FMLP or C5a, showing that it can be used to inactivate NAP-1/IL-8 selectively. The effect of antiNAP-1/IL-8 on the neutrophil-stimulating activity in the culture supernatants of PBMC from five RA patients is shown in Table II $B$. On average, the antiserum inhibited the neutrophilstimulating activity that was released spontaneously or after stimulation with LPS, RF-IC, zymosan, or IL-1 between 92 and $99 \%$. This indicates that virtually all neutrophil-stimulating activity released by the PBMC was due to NAP-1/IL-8.

Effect of IFN-gamma. When studying the responses to various cytokines, we were surprised to find that IFN-gamma, which is a generally accepted macrophage activator (23), decreased the spontaneous release of neutrophil-stimulating activity by SFMC (Fig. $3 \mathrm{~B}$ ). This effect was also observed in stimulated PBMC. As shown in Fig. 4, IFN-gamma inhibited the enhancing effect of LPS and IL-1 on the production of neutrophil-stimulating activity by PBMC from both RA patients and healthy controls.

Effect of indomethacin and glucocorticoids. It is well known that the release and oxygenation of arachidonic acid is stimulated in monocytes from RA (24-28). We have, therefore, examined the effect of inhibition of prostaglandin synthesis (by indomethacin) and the presumed inhibition of phospholipase $\mathrm{A}_{2}$ (by dexamethasone) on the production of neutrophil-stimulating activity by PBMC. Indomethacin clearly enhanced the zymosan-induced release of neutrophil-stimulating activity from PBMC of normal individuals and RA patients (Fig. 5). In unstimulated and LPS-stimulated PBMC the effect of indomethacin was minimal.

By contrast, as shown in Fig. 6, the strong inductive effect of zymosan, in either control or RA PBMC, was almost totally inhibited by dexamethasone at concentrations ranging between $10^{-9}-10^{-5} \mathrm{M}$. Since glucocorticoids are often used intra- 

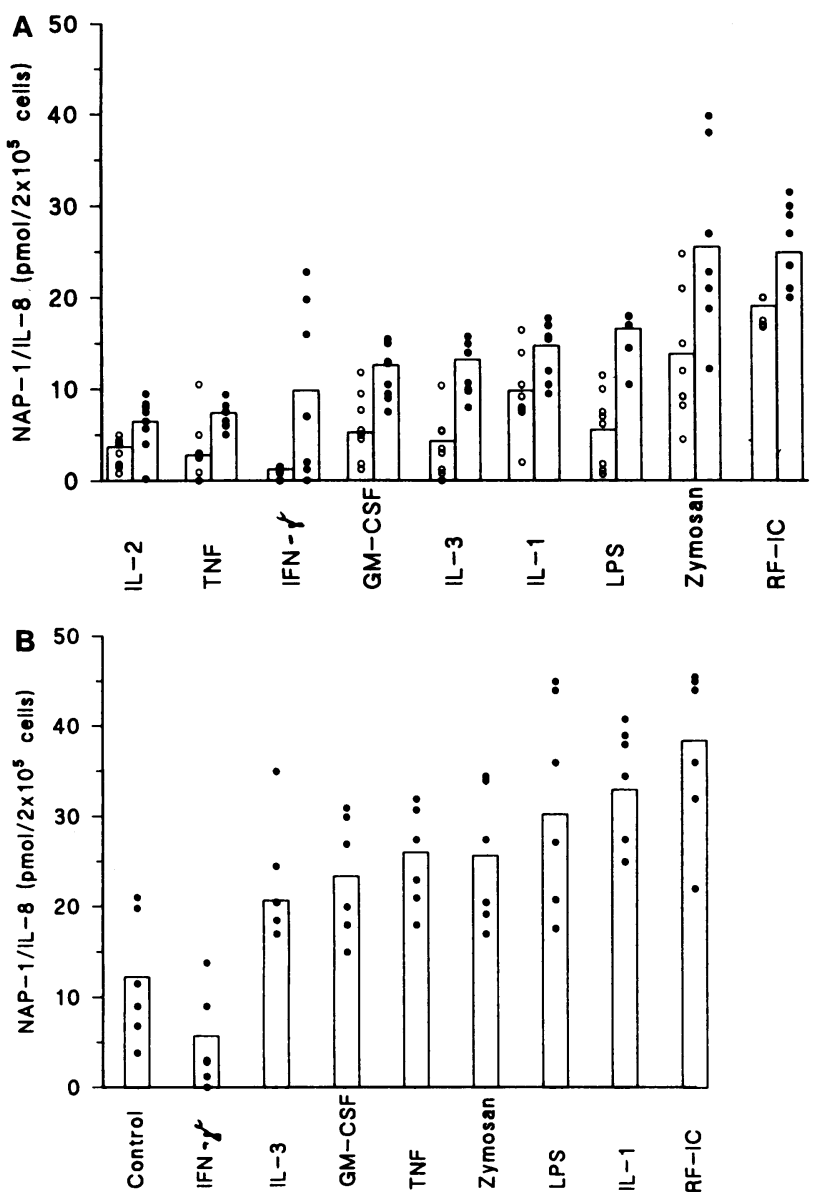

Figure 3. Effect of various cytokines, LPS, zymosan, and RF-IC on production of neutrophil-stimulating activity by mononuclear cells. (Upper) PBMC from eight normal individuals (0) and eight RA patients $(\bullet)$ were cultured with or without the indicated agent for 48 h. Neutrophil-stimulating activity is presented as the difference between release from stimulated and unstimulated cells. Single values (circles) and means (columns) are shown. Statistical difference between effects on cells from normal controls and RA patients was $P$ $=0.01$ for IL-2, $P<0.05$ for TNF, $P<0.001$ for IFN-gamma, $P$ $=0.02$ for GM-CSF, $P=0.002$ for IL-3, $P=0.01$ for IL-1, $P=0.001$ for LPS, $P=0.005$ for zymosan, and $P<0.001$ for RF-IC. (Lower) SFMC from six RA patients were incubated with or without the indicated agent for $48 \mathrm{~h}$. Statistical difference between stimulated and spontaneous release of neutrophil-stimulating activity was $P=0.05$ for IFN-gamma, $P<0.05$ for IL-3, $P<0.02$ for GM-CSF and zymosan, $P=0.005$ for TNF, and $P<0.005$ for LPS, IL-1, and RF-IC.

articularly to treat synovitis, we studied the release of neutrophil-stimulating activity by SFMC from 4 RA patients before and 2 wk after intraarticular injection of $5 \mathrm{mg}$ betamethasonedipropionate and $2 \mathrm{mg}$ betamethasone-disodiumphosphate. This treatment dramatically reduced the spontaneous and LPS-dependent release of neutrophil-stimulating activity and decreased the total number of leukocytes as well as the percentage of neutrophils in the synovial fluid (Table III).

\section{Discussion}

In this study NAP-1/IL-8 production by mononuclear cells from RA patients and healthy individuals was compared. It
Table I. Induction of NAP-1/IL-8 Production in PBMC by Different Immune Complexes

\begin{tabular}{lcccr}
\hline & \multicolumn{5}{c}{ NAP-1/IL-8 } \\
\cline { 2 - 5 } Subjects & No stimulus & RF-IC & IC & IgG-IC \\
\hline & \multicolumn{4}{c}{$p m o l / 2 \times 10^{5}$ monocytes* } \\
Controls & & & & \\
Experiment 1 & 1.4 & 6.75 & 6.0 & 7.7 \\
Experiment 2 & 0 & 9.6 & 8.9 & 14.0 \\
Experiment 3 & 0.55 & 8.35 & 7.2 & 11.9 \\
RA patients & & & & \\
Experiment 1 & 7.0 & 23.5 & 25.5 & 41.5 \\
Experiment 2 & 10.5 & 44.5 & 37.5 & 43.0 \\
Experiment 3 & 4.0 & 21.5 & 18.0 & 10.5 \\
& & & & \\
\hline
\end{tabular}

* Mean of quadruplicate samples of $2 \times 10^{5}$ PBMC cultured for $48 \mathrm{~h}$.

was found that the cells from RA patients produce high amounts of neutrophil-stimulating activity, and that this activity can be attributed almost entirely to NAP-1/IL-8. Cultures of mononuclear cells from bone marrow, peripheral blood, and synovial fluid were compared. By far the highest production, both in the absence and presence of added stimuli, was obtained with cells isolated from synovial fluid. Furthermore, NAP-1/IL-8 release from PBMC of RA patients was severalfold higher than from PBMC of healthy individuals $(P$ $<0.001$ ). LPS, IL-1, zymosan, and immune complexes (including rheumatoid factor-containing immune complexes) were found to be very effective inducers of NAP- $1 /$ IL- 8 production.

Our results suggest that rheumatoid factor-containing immune complexes and IL-1, which are produced in large amounts in the inflamed synovium (29-32), are likely to be important mediators of NAP-1/IL-8 generation in rheumatoid joints. The comparison of the yield of NAP-1/IL- 8 in cells from the bone marrow, peripheral blood, and synovial fluid indicates that differentiation and activation increase the capacity of the mononuclear phagocytes to produce NAP-1/IL-8. The high level of spontaneous NAP-1/IL-8 release by SFMC suggests that these cells are activated and that inducers are present in the synovial fluid. This notion is supported by the recent finding of appreciable amounts of NAP-1/IL-8 in synovial fluids from RA patients. Enhanced HLA-DR expression, another parameter of activation, has been observed in synovial fluid and synovial membrane mononuclear cells from arthritic joints (33-35).

In addition to $\mathrm{C} 5 \mathrm{a}$, which is generated mainly through immune complex-dependent complement activation, NAP-1/IL8 must be considered a major mediator of the continuous accumulation and activation of neutrophils, which contributes to the amplification and perpetuation of the inflammatory process. Besides mononuclear phagocytes, fibroblasts and synoviocytes have been shown to produce NAP-1/IL-8 upon stimulation with IL-1 $(10,16,36)$, indicating that this neutrophil attractant is presumably also released by the resident cells of the inflamed joint. Since NAP-1/IL- 8 is much more resistant to inactivation by peptidases and proteases than C5a (37), it is likely to retain its activity in the synovial fluid and to have a 
Table II A. Effect of Anti-NAP-1/IL-8 on Elastase Release by Human Neutrophils Induced by Chemotactic Peptides

\begin{tabular}{lccccc}
\hline & & \multicolumn{2}{c}{ Anti-NAP-1 } & & \\
\cline { 3 - 4 } Peptide & Concentration & - & + & $(\%)$ & $n$ \\
\hline \multirow{2}{*}{ NAP-1/IL-8 } & $n M$ & & & & \\
& 1 & $145 \pm 8^{*}$ & 0 & 100 & 4 \\
& 3 & $352 \pm 14$ & 0 & 100 & 4 \\
& 10 & $603 \pm 51$ & 2 & 99.7 & 4 \\
FMLP & 30 & $816 \pm 104$ & $311 \pm 239$ & 61.8 & 4 \\
& 3 & $143 \pm 77$ & $125 \pm 79$ & 12.8 & 3 \\
C5a & 10 & $914 \pm 19$ & $833 \pm 58$ & 8.9 & 3 \\
& 0.3 & 634 & 573 & 9.5 & 2 \\
& 1 & 1466 & 1430 & 2.5 & 2
\end{tabular}

* Relative fluorescence units. Means $\pm \mathrm{SD}$; $n$, number of experiments with different neutrophil preparations.

Table II B. Effect of Anti-NAP-1/IL-8 on Elastase Release from Human Neutrophils by PBMC Culture Supernatants

\begin{tabular}{ccccccc}
\hline & & \multicolumn{5}{c}{ Stimulus in PBMC culture } \\
\cline { 3 - 7 } Ratient & $\begin{array}{c}\text { Anti- } \\
\text { NAP-1 }\end{array}$ & None & LPS & RF-IC & Zymosan & IL-1 \\
\hline 1 & - & $58^{*}$ & 56 & 172 & 24 & \\
& + & 9.5 & 7.5 & 25 & 3 & \\
& & $(84)$ & $(87)$ & $(85)$ & $(88)$ & \\
2 & - & 115 & 128 & & 56 & \\
& + & 20 & 26 & & 3 & \\
& & $(83)$ & $(80)$ & & $(94)$ & \\
3 & - & 24 & 216 & 322 & 92 & \\
& + & 0 & 6 & 37.5 & 1.5 & \\
& & $(100)$ & $(97)$ & $(88)$ & $(98)$ & \\
4 & - & 5 & 65 & 52 & 156 & 53 \\
& + & 0 & 1 & 0.5 & 2 & 0 \\
& & $(100)$ & $(98)$ & $(99)$ & $(99)$ & $(100)$ \\
5 & - & 121 & 242 & 194 & & 351 \\
& + & 2 & 3 & 1.5 & & 6 \\
& & $(98)$ & $(99)$ & $(99)$ & & $(98)$ \\
& & & & & &
\end{tabular}

* Values are relative fluorescence units; in parenthesis, values are percent inhibition.

long lasting effect on neutrophil recruitment. In vivo studies in rabbits have shown that NAP-1/IL-8 is chemotactic for neutrophils for up to $10 \mathrm{~h}$ after intradermal injection $(17,38)$.

In this study, we confirmed that several cytokines are strong inducers of NAP-1/IL-8 production. IL-2, IL-3, TNF, GMCSF, and especially IL-1 were stimulatory. Secondary effects of factors released from stimulated mononuclear cells other than monocytes are unlikely, since, as previously shown (37), monocytes are the predominant producers of NAP-1/IL- 8 and very similar results were obtained when isolated monocytes instead of mononuclear cells were used. IFN-gamma, in contrast to the above cytokines, inhibited the spontaneous formation of NAP1/IL-8 by SFMC, and the stimulated release by PBMC from normal individuals and RA patients. Since the effect of IFNgamma was very pronounced on SFMC from rheumatic joints,

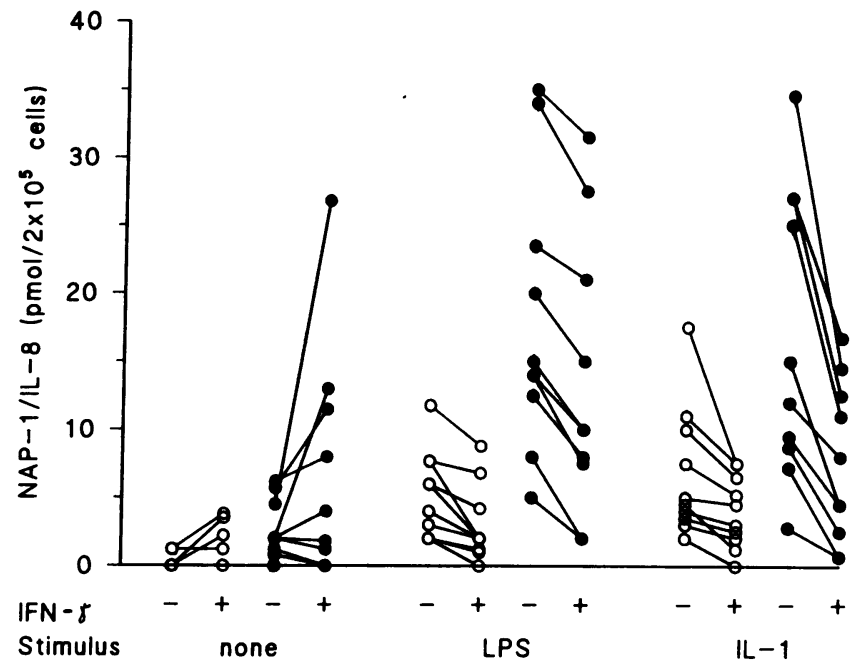

Figure 4. Effect of IFN-gamma. PBMC from 10 normal individuals $(0)$ and $10 \mathrm{RA}$ patients $(\bullet)$ were incubated with or without IFNgamma $(100 \mathrm{U} / \mathrm{ml})$ for $1 \mathrm{~h}$ and then cultured for $48 \mathrm{~h}$ in the absence and presence of LPS $(100 \mathrm{ng} / \mathrm{ml})$ or IL-1 $(10 \mathrm{ng} / \mathrm{ml})$. A statistical significant difference between corresponding cultures with and without IFN-gamma pretreatment was found for spontaneous $(P$ $<0.001)$, LPS- $(P<0.01)$, and IL-1-stimulated $(P<0.001)$ release from normal PBMC and for IL-1-stimulated release from RA PBMC $(P<0.05)$

this observation may have important pathophysiological and possibly therapeutical implications. It has in fact been reported that the production of IFN-gamma by mononuclear cells is decreased or defective in RA (39-41), resulting in lower levels of IFN-gamma in the synovial fluid $(42,43)$. In addition, Ghezzi and Dinarello (44) recently showed that IFN-gamma specifically downregulates the autocrine IL-1-dependent production of IL-1 by PBMC. It is conceivable that IFN-gamma exerts a regulatory function by lowering the self-perpetuating production of IL-1, and consequently the IL-1-induced NAP-

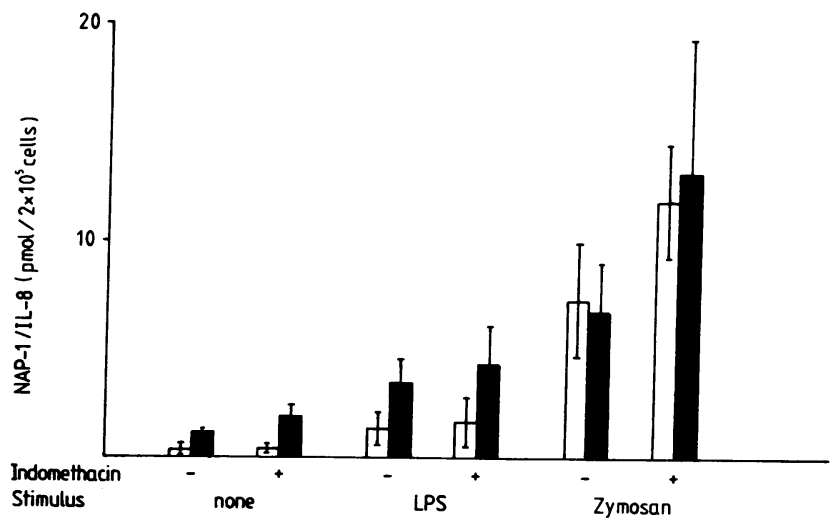

Figure 5. Effect of indomethacin. PBMC from four normal subjects (open columns) and four RA patients (solid columns) were incubated with or without $20 \mu \mathrm{M}$ indomethacin for $1 \mathrm{~h}$, and were then cultured for $48 \mathrm{~h}$ in the absence and presence of LPS $(100 \mathrm{ng} / \mathrm{ml})$ or zymosan $(1 \mathrm{mg} / \mathrm{ml})$. A statistical significant difference between corresponding cultures with and without indomethacin was found for spontaneous release from RA PBMC and for zymosan-stimulated release from control and RA PBMC $(P=0.05)$. 
Table III. Effect of Intraarticular Glucocorticoid Injection on NAP-1/IL-8 Production by Cultured SFMC

\begin{tabular}{|c|c|c|c|c|c|c|c|c|}
\hline \multirow[b]{3}{*}{$\begin{array}{c}\text { RA } \\
\text { patient }\end{array}$} & \multicolumn{4}{|c|}{ Before injection } & \multicolumn{4}{|c|}{$14 \mathrm{~d}$ after i.a. injection } \\
\hline & \multicolumn{2}{|c|}{ NAP-1/IL-8* } & \multicolumn{2}{|c|}{ Cell recovery } & \multicolumn{2}{|c|}{ NAP-1/IL-8* } & \multicolumn{2}{|c|}{ Cell recovery } \\
\hline & $\begin{array}{c}\text { No } \\
\text { stimulus }\end{array}$ & LPS & $\begin{array}{c}\text { Total cells/ } \\
\mu \mathrm{l}\end{array}$ & $\begin{array}{l}\text { PMN } \\
(\%)\end{array}$ & $\begin{array}{c}\text { No } \\
\text { stimulus }\end{array}$ & LPS & $\begin{array}{c}\text { Total cells/ } \\
\mu \mathrm{l}\end{array}$ & $\begin{array}{l}\text { PMN } \\
(\%)\end{array}$ \\
\hline 1 & 7.2 & 16.0 & 26,000 & 92 & 0.8 & 3.0 & 14,000 & 72 \\
\hline 2 & 14.5 & 36.0 & 12,000 & 94 & 1.6 & 11.0 & 8,000 & 84 \\
\hline 3 & 9.6 & 21.0 & 18,000 & 91 & 1.0 & 5.6 & 12,000 & 65 \\
\hline 4 & 12.5 & 44.0 & 21,000 & 94 & 0.7 & 14.0 & 14,000 & 56 \\
\hline
\end{tabular}

* NAP-1/IL-8 (pmol/2 $\times 10^{5}$ monocytes). Mean values from quadruplicate 48 -h cultures of $2 \times 10^{5} \mathrm{SFMC}$ with or without $\mathrm{LPS}(100 \mathrm{ng} / \mathrm{ml})$.

$1 /$ IL- 8 release in the RA synovium. Contrary to the LPS-induced IL-1 production where IFN-gamma had a stimulatory effect (44), LPS-stimulated NAP-1/IL-8 release was inhibited as well. As evidence for a major role for NAP-1/IL-8 in chronic inflammation is increasing, the search for possible physiological inhibitors and antagonists becomes an important goal. Preliminary results of a study in progress on NAP-1/IL-8 release by PBMC from RA patients treated with hrIFN-gamma have shown that in some patients that responded to the treatment, NAP-1/IL-8 production was downregulated.

Mononuclear cells from patients with rheumatoid arthritis produce high amounts of prostaglandins (23-25). In this study, inhibition of cyclooxygenase by indomethacin tended to enhance the spontaneous and stimulated release of NAP-1/IL-8 by PBMC. This observation suggests that $\mathrm{PGE}_{2}$ and possibly other prostanoids may inhibit NAP-1/IL- 8 production, and that, therefore, treatment of RA patients with nonsteroidal antiinflammatory drugs may favor neutrophil recruitment and activation. A quite different situation was obtained with dexamethasone, which almost completely inhibited phagocytosisinduced NAP-1/IL-8 at concentrations as low as $10^{-9} \mathrm{M}$. Accordingly, application of intraarticular glucocorticoids resulted in a dramatic reduction of both spontaneous and stimulated NAP-1/IL-8 production by cultured SFMC obtained from the treated joints. The treatment also decreased the number of neu-

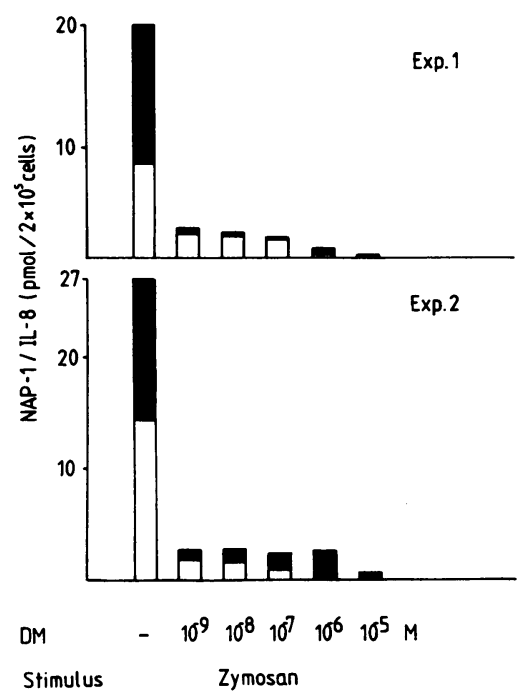

Figure 6. Effect of dexamethasone $(D M)$. PBMC from two normal individuals (open columns) and two RA patients (solid columns) were preincubated for $1 \mathrm{~h}$ with or without dexamethasone $\left(10^{-9}\right.$ $\left.10^{-5} \mathrm{M}\right)$, and were then stimulated with zymosan $(1 \mathrm{mg} / \mathrm{ml})$ for $48 \mathrm{~h}$. trophils in the synovial fluid, which may result from a direct effect on NAP-1/IL-8 production or from inhibition of IL-1 synthesis.

This study suggests a role for NAP-1/IL- 8 in the recruitment and activation of neutrophils in rheumatoid joints and directs attention towards the possible effects of nonsteroidal antiinflammatory drugs, glucocorticoids, and IFN-gamma in the modulation of this proinflammatory process. It must, however, be kept in mind that our study so far was limited to the production of NAP-1/IL-8 by mononuclear cells from RA patients. The behavior of PBMC and SFMC from patients with other forms of chronic inflammatory joint disease is currently under investigation.

\section{Acknowledgments}

We thank Ms. Marianne Zwicker and Ms. Andrea Blaser for expert technical assistance and Ms. Margrit Rhyn for secretarial work.

This work was supported in part by a grant of the Foundation Jean \& Linette Warnery, Morges, Switzerland to Dr. Baggiolini.

\section{References}

1. Fernandez, H. N., P. M. Henson, A. Otani, and T. E. Hugli. 1978. Chemotactic response to human $\mathrm{C} 3 \mathrm{a}$ and $\mathrm{C} 5 \mathrm{a}$ anaphylatoxins. I. Evaluation of $\mathrm{C} 3 \mathrm{a}$ and C5a leukotaxis in vitro and under stimulated in vivo conditions. J. Immunol. 120:109-115.

2. Lee, T. C., and F. Snyder. 1985. Function, metabolism and regulation of platelet activating factor and related ether lipids. In Phospholipids and Cellular Regulation. J. F. Kuo, editor. Boca Raton: CRC Press, Boca Raton, FL. 1-39.

3. Ford Hutchinson, A. W., M. A. Bray, M. V. Doig, M. E. Shipley, and M. J. Smith. 1980. Leukotriene B, a potent chemokinetic and aggregating substance released from polymorphonuclear leukocytes. Nature (Lond.). 286:264-265.

4. Le, J., and J. Vilcek. 1987. Tumor necrosis factor and interleukin 1: cytokines with multiple overlapping biological activities. Lab. Invest. 56:234-248.

5. Shalaby, M. R., B. B. Aggarwal, E. Rinderknecht, L. P. Svedersky, B. S. Finkle, and M. A. Palladino, Jr. 1985. Activation of human polymorphonuclear neutrophil functions by interferon-gamma and tumor necrosis factors. $\mathrm{J}$. Immunol. 135:2069-2073.

6. Baggiolini, M., J. Schnyder, U. Bretz, B. Dewald, and W. Ruch. 1980. Cellular mechanisms of proteinase release from inflammatory cells and the degradation of extracellular proteins. Ciba. Found. Symp. 75:105-121.

7. Yoshimura, T., K. Matsushima, S. Tanaka, E. A. Robinson, E. Appella, J. J. Oppenheim, and E. J. Leonard. 1987. Purification of a human monocytederived neutrophil chemotactic factor that has peptide sequence similarity to other host defense cytokines. Proc. Natl. Acad. Sci. USA. 84:9233-9237.

8. Gregory, H., J. Young, J. M. Schroeder, U. Mrowietz, and E. Christophers. 1988. Structure determination of a human lymphocyte derived neutrophil activating peptide (LYNAP). Biochem. Biophys. Res. Commun. 151:883-890.

9. Walz, A., P. Peveri, H. Aschauer, and M. Baggiolini. 1987. Purification and amino acid sequencing of NAF, a novel neutrophil-activating factor produced by monocytes. Biochem. Biophys. Res. Commun. 149:755-761. 
10. Baggiolini, M., A. Walz, and S. L. Kunkel. 1989. Neutrophil-activating peptide-1/interleukin 8, a novel cytokine that activates neutrophils. J. Clin. Invest. 84:1045-1049.

11. Bevilacqua, M. P., J. S. Pober, M. E. Wheeler, R. S. Cotran, and M. A. Gimbrone, Jr. 1985. Interleukin 1 acts on cultured human vascular endothelium to increase the adhesion of polymorphonuclear leukocytes, monocytes, and related leukocyte cell lines. J. Clin. Invest. 76:2003-2011.

12. Pohlman, T. H., K. A. Stanness, P. G. Beatty, H. D. Ochs, and J. M. Harlan. 1986. An endothelial cell surface factor(s) induced in vitro by lipopolysaccharide, interleukin 1, and tumor necrosis factor-alpha increases neutrophil adherence by a CDw18-dependent mechanism. J. Immunol. 136:4548-4553.

13. Strieter, R. M., S. L. Kunkel, H. J. Showell, and R. M. Marks. 1988. Monokine-induced gene expression of a human endothelial cell-derived neutrophil chemotactic factor. Biochem. Biophys. Res. Commun. 156:1340-1345.

14. Schroeder, J. M., and E. Christophers. 1989. Secretion of novel and homologous neutrophil-activating peptides by LPS-stimulated human endothelial cells. J. Immunol. 142:244-251.

15. Strieter, R. M., S. H. Phan, H. J. Showell, D. G. Remick, J. P. Lynch, M. Genord, C. Raiford, M. Eskandari, R. M. Marks, and S. L. Kunkel. 1989. Monokine-induced neutrophil chemotactic factor gene expression in human fibroblasts. J. Biol. Chem. 264:10621-10626.

16. Watson, M. L., J. Westwick, N. J. Fincham, and R. D. Camp. 1988. Elevation of PMN cytosolic free calcium and locomotion stimulated by novel peptides from IL-1-treated human synovial cell cultures. Biochem. Biophys. Res. Commun. 155:1154-1160.

17. Colditz, I., R. Zwahlen, B. Dewald, and M. Baggiolini. 1989. In vivo inflammatory activity of neutrophil-activating factor, a novel chemotactic peptide derived from human monocytes. Am. J. Pathol. 134:755-760.

18. Arnett, F. C., S. M. Edworthy, D. A. Bloch, D. J. McShane, J. F. Fries, N. S. Cooper, L. A. Healey, S. R. Kaplan, M. H. Liang, H. S. Luthra, T. A Medsger, D. M. Mitchell, D. H. Neustadt, R. S. Pinals, J. G. Schaller, J. T. Sharp R. L. Wilder, and G. G. Hunder. 1988. The American Rheumatism Association 1987 revised criteria for the classification of rheumatoid arthritis. Arthritis Rheum. 31:315-324.

19. Boyum, A. 1976. Isolation of lymphocytes, granulocytes and macrophages. Scand. J. Immunol. 5:9-15.

20. Koski, J. R., Poplak, D. G. and Blaese, R. M. A. 1976. Nonspecific Esterase Stain for the Identification of Monocytes and Macrophages. Academic Press. New York. 359 pp.

21. Dewald, B., and M. Baggiolini. 1987. Evaluation of PAF antagonists using human neutrophils in a microtiter plate assay. Biochem. Pharmacol. 36:25052510.

22. Lindley, I., H. Aschauer, J. M. Seifert, C. Lam, W. Brunowsky, E. Kownatzki, M. Thelen, P. Peveri, B. Dewald, V. von Tscharner, A. Walz, and M. Baggiolini. 1988. Synthesis and expression in E. coli of the gene of NAF, a monocyte-derived neutrophil-activating factor. Biological equivalence between natural and recombinant NAF. Proc. Natl. Acad. Sci. USA. 85:9199-9203.

23. Murray, H. W., D. Scavuzzo, J. L. Jacobs, M. H. Kaplan, D. M. Libby, J. Schindler, and R. B. Roberts. 1987. In vitro and in vivo activation of human mononuclear phagocytes by interferon-gamma. Studies with normal and AIDS monocytes. J. Immunol. 138:2457-2462.

24. Seitz, M., W. Deimann, N. Gram, W. Hunstein, and D. Gemsa. 1982. Characterization of blood mononuclear cells of rheumatoid arthritis patients. I. Depressed lymphocyte proliferation and enhanced prostanoid release from monocytes. Clin. Immunol. Immunopathol. 25:405-416.

25. Seitz, M., and W. Hunstein. 1985. Enhanced prostanoid release from monocytes of patients with rheumatoid arthritis and active systemic lupus erythematosus. Ann. Rheum. Dis. 44:438-445.

26. Cruchaud, A., J. P. Despont, A. Roth, and J. M. Dayer. 1984. Phagocytosis, bactericidal capacity, and PGE2 production of monocytes in systemic lupus erythematosus and rheumatoid arthritis. Diagn. Immunol. 2:203-212.
27. Bomalaski, J. S., M. A. Clark, and R. B. Zurier. 1986. Enhanced phospholipase activity in peripheral blood monocytes from patients with rheumatoid arthritis. Arthritis Rheum. 29:312-318.

28. Bomalaski, J. S., C. S. Goldstein, A. T. Dailey, S. D. Douglas, and R. B. Zurier. 1986. Uptake of fatty acids and their mobilization from phospholipids in cultured monocyte-macrophages from rheumatoid arthritis patients. Clin. Immunol. Immunopathol. 39:198-212.

29. Smiley, J. D., C. Sachs, and M. Ziff. 1968. In vitro synthesis of immunoglobulin by rheumatoid synovial membrane. J. Clin. Invest. 47:624-632.

30. Munthe, E., and J. B. Natvig. 1972. Immunoglobulin classes, subclasses and complexes of IgG rheumatoid factor in rheumatoid plasma cells. Clin. Exp. Immunol. 12:55-70.

31. Waalen, K., G. W. Duff, O. Forre, E. Dickens, L. Kvarnes, and G. Nuki. 1986. Interleukin 1 activity produced by human rheumatoid and normal dendritic cells. Scand. J. Immunol. 23:365-371.

32. Bendtzen, K., J. Petersen, J. Halkjaer Kristensen, and T. Ingemann-Hansen. 1985. Interleukin-1-like activities in synovial fluids of patients with rheumatoid arthritis and traumatic synovitis. Rheumatol. Int. 5:79-82.

33. Klareskog, L., U. Forsum, U. K. Malmnas Tjernlund, D. Kabelitz, and A. Wigren. 1981. Appearance of anti-HLA-DR-reactive cells in normal and rheumatoid synovial tissue. Scand. J. Immunol. 14:183-192.

34. Burmester, G. R., A. Dimitriu Bona, S. J. Waters, and R. J. Winchester. 1983. Identification of three major synovial lining cell populations by monoclonal antibodies directed to Ia antigens and antigens associated with monocytes/ macrophages and fibroblasts. Scand. J. Immunol. 17:69-82.

35. Firestein, G. S., and N. J. Zvaifler. 1987. Peripheral blood and synovial fluid monocyte activation in inflammatory arthritis. I. A cytofluorographic study of monocyte differentiation antigens and class II antigens and their regulation by gamma-interferon. Arthritis Rheum. 30:857-863.

36. Golds, E. E., P. Mason, and P. Nyirkos. 1989. Inflammatory cytokines induce synthesis and secretion of gro protein and a neutrophil chemotactic factor but not beta2-microglobulin in human synovial cells and fibroblasts. Biochem. J. 259:585-588.

37. Peveri, P., A. Walz, B. Dewald, and M. Baggiolini. 1988. A novel neutrophil-activating factor produced by human mononuclear phagocytes. J. Exp. Med. 167:1547-1559.

38. Colditz, I., R. D. Zwahlen, and M. Baggiolini. 1990. Neutrophil accumulation and plasma leakage induced in vivo by neutrophil-activating peptide- $1 J$. Leukocyte Biol. 48: 129-137.

39. Hasler, F., H. G. Bluestein, N. J. Zvaifler, and L. B. Epstein. 1983. Analysis of the defects responsible for the impaired regulation of Epstein-Barr virus-induced B cell proliferation by rheumatoid arthritis lymphocytes. I. Diminished gamma interferon production in response to autologous stimulation. J. Exp Med. 157:173-188.

40. Seitz, M., I. Napierski, R. Augustin, W. Hunstein, and H. Kirchner. 1987. Reduced production of interferon alpha and interferon gamma in leukocyte cultures from patients with active rheumatoid arthritis. Scand.J. Rheumatol. 16:257-262.

41. Stolzenburg H., A. Binz, A. Fontana, M. Felder, and F.-J. Wagenhäuser. 1988. Impaired mitogen-induced interferon-gamma production in rheumatoid arthritis and related diseases. Scand. J. Immunol. 27:73-81.

42. Husby, G., and R. C. Williams, Jr. 1985. Immunohistochemical studies of interleukin-2 and gamma-interferon in rheumatoid arthritis. Arthritis Rheum. 28:174-181.

43. Firestein, G. S., and N. J. Zvaifler. 1987. Peripheral blood and synovial fluid monocyte activation in inflammatory arthritis. II. Low levels of synovia fluid and synovial tissue interferon suggest that gamma-interferon is not the primary macrophage activating factor. Arthritis Rheum. 30:864-871.

44. Ghezzi, P., and C. A. Dinarello. 1988. IL-1 induces IL-1. III. Specific inhibition of IL-1 production by IFN-gamma. J. Immunol. 140:4238-4244. 